\title{
Effective immunosuppressive therapy in a patient with primary pulmonary hypertension
}

\author{
F Bellotto, P Chiavacci, F Laveder, A Angelini, G Thiene, R Marcolongo
}

\begin{abstract}
The case history is described of a young woman who presented with primary pulmonary hypertension and non-specific inflammatory signs. The patient received prolonged immunosuppressive treatment with low dose methotrexate and prednisone without any vasodilator agent. After one year the pulmonary artery pressure fell from a mean value of $47 \mathrm{~mm}$ $\mathrm{Hg}$ to $30 \mathrm{~mm} \mathrm{Hg}$ and there was a corresponding clinical response. This case suggests that, in patients with pulmonary hypertension of unknown origin, immunopathogenetic factors should be sought in order to consider the utility of immunosuppressive therapy.

(Thorax 1999;54:372-374)
\end{abstract}

Keywords: pulmonary hypertension; methotrexate; transforming growth factor $\beta$

Primary pulmonary hypertension $(\mathrm{PPH})$ is a rare disease of unknown origin that should be suspected in any young patient who presents with unexplained effort dyspnoea and electrocardiographic signs of right ventricular hypertrophy in the apparent absence of any underlying cause. ${ }^{1}$ Pulmonary hypertension clinically and histologically similar to $\mathrm{PPH}$ has been described in association with connective tissue diseases and other immunological disorders, also in the absence of any parenchymal lung involvement. ${ }^{2}$ Primary forms usually show a rapidly progressive course despite treatment, with a mean survival of 2.5 years. ${ }^{3}$

We describe a patient with PPH who, after treatment with immunosuppressive therapy, showed a clinical improvement.

School of Medicine, Italy

Correspondence to:

Dr R Marcolongo, Università degli Studi di Padova, Dipartimento di Medicina

Clinica e Sperimentale,

Servizio di Immunologia

Clinica, Via Giustiniani 2,

35128 Padova, Italy.

Received 27 May 1997

Returned to authors

17 September 1997

Revised version received

14 October 1997

Accepted for publication

10 November 1997 antinuclear (ANA and ENA) and antiphospholipid antibodies, rheumatoid factor, ANCA and other autoantibodies, HIV and other infectious agents were always negative. The patient had never been pregnant nor used appetite suppressants or any other drug potentially able to induce pulmonary hypertension. ${ }^{1}$ There were no signs suggestive of connective tissue disease.

Laboratory tests gave the following results: erythrocyte sedimentation rate, $29 \mathrm{~mm} / \mathrm{h}$; fibrinogen, $5.32 \mathrm{~g} / 1$ (normal $2.0-4.0 \mathrm{~g} / \mathrm{l}$ ); antithrombin III $1.42 \mathrm{IU} / \mathrm{ml}$ (normal 0.8-1.2); positive indirect antiglobulin test; serum IgE, $1.817 \mathrm{kU} / 1$ (normal <200) with negative RAST; serum IgG, $19.30 \mathrm{~g} / \mathrm{l}$ (normal $8.0-15.0 \mathrm{~g} / \mathrm{l}$ ); serum IgA, $0.32 \mathrm{~g} / 1$ (normal $1.00-4.90 \mathrm{~g} / \mathrm{l}$ ); ferritin, $1808 \mathrm{ng} / 1$ (normal 4-233 ng/l); positivity for HLA-DR4 antigen; moderate increase in peripheral blood CD8+ lymphocytes. Other routine tests were negative or normal.

Lung scans with $99 \mathrm{~m}$-technetium labelled albumin macroaggregates and 133-xenon gas and deep vein Doppler ultrasonography of the lower extremities were normal. The electrocardiogram, which had been normal six months earlier, showed signs of right ventricular (RV) pressure overload. The chest radiograph showed normal lung fields and a marked distension of the main pulmonary artery. Echocardiography revealed moderate RV hypertrophy and dilatation, with an RV ejection fraction of $39 \%$, mild tricuspid incompetence, and an estimated pulmonary pressure of $75 \mathrm{~mm} \mathrm{Hg}$. Spirometric findings were normal: $\mathrm{FEV}_{1} 2.431$ (94\% of predicted normal) and FVC 2.601 (119\% of predicted normal), FRC 2.081 , TLC 4.161 (101\% of predicted normal). Arterial blood gas tensions on room air were $\mathrm{PaO}_{2} 94 \mathrm{~mm} \mathrm{Hg}(12.5 \mathrm{kPa}), \mathrm{SaO}_{2} 97 \%$, $\mathrm{pH} 7.41, \mathrm{PaCO}_{2} 40 \mathrm{~mm} \mathrm{Hg}(5.3 \mathrm{kPa})$; TLCO was $23.5 \mathrm{ml} \mathrm{CO} / \mathrm{min} / \mathrm{mm} \mathrm{Hg}$. Right heart catheterisation showed a pulmonary arterial pressure of 65/30 (mean 47) $\mathrm{mm} \mathrm{Hg}$, pulmonary capillary wedge pressure of $3 \mathrm{~mm} \mathrm{Hg}$, cardiac output $3.6 \mathrm{1} / \mathrm{min}$, and vascular resistance of 12.2 Wood units. Mean values of pulmonary arterial and capillary wedge pressures and vascular resistance were substantially unaffected by prolonged intravenous infusion of diltiazem (15 mg/kg/min for four hours) or supplemental oxygen. 

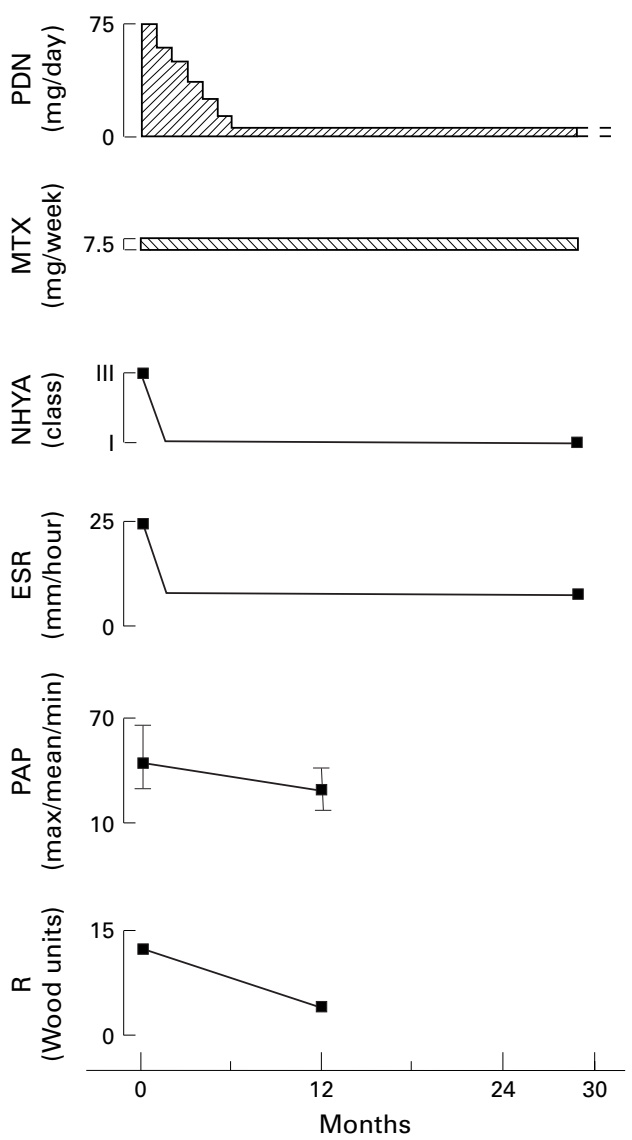

Figure 1 Relationship between the clinical course and immunosuppressive treatment. $P D N=$ prednisone; $M T X=$ methotrexate $; E S R=$ erythrocyte sedimentation rate $; P A P$ $=$ pulmonary artery pressure; $R=$ vascular resistance.

Open lung biopsy specimens showed diffuse involvement of small arteries and arterioles, intimal fibrocellular proliferation and severe luminal narrowing; there were no signs of inflammatory, thromboembolic, or pulmonary veno-occlusive disease, suggesting the diagnosis of $\mathrm{PPH}{ }^{4}$ Immunofluorescence staining for immunoglobulins, complement, and fibrinogen was negative.

Given the rapid progression of the disease, the lack of any acute reactivity to vasodilator agents, and the suspicion of an immune mediated pathogenetic mechanism because of the persistent signs of systemic inflammation, immunosuppressive therapy with oral prednisone $(1.5 \mathrm{mg} / \mathrm{kg} /$ day for one month gradually tapering to $5 \mathrm{mg}$ /day over six months) and methotrexate $(7.5 \mathrm{mg} /$ week over 36 hours followed by low dose folinic acid, $2.5 \mathrm{mg} /$ week) was administered for one year with the patient's informed consent.

The patient received only immunosuppressive treatment without any vasodilator or anticoagulation. She became completely asymptomatic in a few weeks, the inflammatory indices steadily returning to within normal ranges. The patient's quality of life improved dramatically (NYHA class I), enabling her to perform even some sports. A right heart catheterisation control after 12 months showed a marked reduction in both pulmonary arterial pressure
(43/18 $\mathrm{mm} \mathrm{Hg}$, mean 30) and vascular resistance (4.36 Wood units) with a cardiac output of $5.5 \mathrm{l} / \mathrm{min}$. The electrocardiographic signs of RV overload were no longer present and RV function appeared normal on echocardiography.

After 30 months methotrexate has been discontinued and the patient, who is still taking prednisone, $5 \mathrm{mg} /$ day, remains well.

\section{Discussion}

In this patient immunosuppressive therapy alone produced a significant decrease in pulmonary vascular resistance, steadily reducing the right heart overload and leading to the complete remission of any sign or symptom of pulmonary hypertension. The variable clinical course of PPH and the fact that some patients will remit spontaneously without treatment have been described previously ${ }^{5}$ so we cannot theoretically exclude the possibility of a spontaneous remission that occurred coincidentally with immunosuppressive treatment. Nevertheless, there is a close temporal relationship between immunosuppression and disease remission (fig 1).

It has recently been shown that plexogenic arteriopathy may result from deregulated endothelial cell growth. ${ }^{6}$ Functionally activated immunocompetent cells surrounding the pulmonary vessels, even in small numbers, may be responsible for the production of local mediators that could favour abnormal endothelial proliferation. In fact, lymphocyte and macrophage released cytokines and growth factors, in addition to the appearance of systemic manifestations, seem also to be involved in pulmonary vascular remodelling. ${ }^{78}$ Both the release of immunologically derived factors such as interleukin 1 and transforming growth factor $\beta$, and of endothelium derived vasoconstrictive factors (thromboxane and endothelin) together with the impaired production of vasodilator molecules (prostacyclin and nitric oxide), might equally account, at least in some cases, for the pathogenesis of PPH. ${ }^{1}$ Thus, pulmonary hypertension and pulmonary vascular remodelling are linked and are mutually self-sustaining. ${ }^{8}$

In patients with NYHA class III or IV and no response to oral calcium channel blockers or a moderate to minimal fall in pulmonary vascular resistance in response to short acting vasodilators, anticoagulation and long term epoprostenol infusions are currently recommended as a possible bridge to lung transplantation. ${ }^{1}$ Although immunosuppressive agents are not usually used in these patients, their rational use may be appropriate in some instances. Indeed, by inhibiting the production of pro-inflammatory and proliferative fibrogenic cytokines, and by controlling both immunologically induced intimal hyperplasia and the general immune response, immunosuppression might theoretically arrest and even relieve vascular obstruction and systemic symptoms, interrupting the vicious circle of "cell growth-vasomotor coupling". Favourable effects have been anecdotally reported in patients with pulmonary 
hypertension associated with autoimmune disorders who have been treated with other immunosuppressive agents such as cyclophosphamide or cyclosporin A. ${ }^{210-12}$ However, the possible efficacy of methotrexate and prednisone in PPH observed in our patient needs to be confirmed.

Since a recent study reported that a subset of patients with PPH may have an immune mediated disease, ${ }^{13}$ we suggest that even minor signs of immune activation should be carefully evaluated in patients with pulmonary hypertension of unknown origin in order to assess the pathogenetic responsibility of immune factors. We suggest further study of the effect of immunosuppressive treatment in the subgroup of patients with severe and uncontrollable $\mathrm{PPH}$, candidates for lung transplantation, to test the hypothesis of a direct drug induced beneficial effect that is not coincident with spontaneous remission.

1 Rubin LJ. Primary pulmonary hypertension. $N$ Engl f Med 1997;336:111-17.

2 Doll NJ, Salvaggio JE. Pulmonary manifestation of collagen vascular disease. Semin Respir Med 1984;5:273-81.
3 D'Alonzo GE, Barst RJ, Ayres SM, et al. Survival in patients with primary pulmonary hypertension. Results from a national prospective registry. Ann Intern Med 1991;115: 343-9.

4 Bjornsson J, Edwards WD. Primary pulmonary hypertension: a histopathologic study of 80 cases. Mayo Clin Proc 1985;60:16-25.

5 Rozkovec A, Montanes P, Oakley CM. Factors that influence the outcome of primary pulmonary hypertension. Br Heart f 1986;55:449-58.

6 Tuder RM, Groves B, Badesch DB, et al. Exuberant endothelial cell growth and elements of inflammation are present in plexiform lesion of pulmonary hypertension. Am f Pathol 1994;144:275-85.

7 Humbert M, Monti G, Brenot F, et al. Increased interleukin-1 and interleukin-6 serum concentrations in severe primary pulmonary hypertension. Am $\mathcal{f}$ Respir Crit care Med 1995;151:1628-31.
Care

8 Voelkel NF, Tuder RM. Cellular and molecular mechanisms in the pathogenesis of severe pulmonary hypertension. Eur Respir F 1995;8:2129-38.

9 Scott PH, Peacock AJ. Cell signalling in pulmonary vascular cells: do not shoot the messenger! Thorax 1996;51:864-6.

10 Goupille P, Fauchier L, Babuty B, et al. Precapillary pulmonary hypertension dramatically improved with high doses of corticosteroids during SLE. $\mathcal{F}$ Rheumatol 1994;21:1976-7.

11 Morelli S, Giordano M, De Marzio P, et al. Pulmonary arterial hypertension responsive to immunosuppressive therapy in SLE. Lupus 1993;2:367-9.

12 Dahl M, Chalmers A, Wade J, et al. Ten year survival of a patient with advanced pulmonary hypertension and MCTD treated with immunosuppressive therapy. $f$ Rheumatol 1992;19:1807-9.

13 Morse JH, Barst RJ, Fotino M, et al. Primary pulmonary hypertension: immunogenetic response to high-mobility group (HMG) prote

\section{LETTERS TO THE EDITOR}

\section{Resection rates in lung cancer}

The recent article by Laroche $e t$ al ${ }^{1}$ is an eloquent reminder that standardised care, hopefully based upon evidence (or at least consensus), can help to ensure that the quality of care is based less on postcode and more upon clinical need. However, the authors and the accompanying editorial ${ }^{2}$ do not emphasise the problems in comparing surgical resection rates for lung cancer with other European countries and the USA.

Much international literature in this area is not directly comparable with that in the UK for at least one reason-namely, that the denominators used may be very different. One study quoted by Laroche et al from the Netherlands described a resection rate for lung cancer of over $20 \%,{ }^{3}$ but used a denominator made up only of patients with a histological diagnosis seen at the related hospitals. The UK data commonly available comprise cases with and without histological verification, including those notified by death certification. The proportion of lung cancer notifications without histological confirmation registered at the West Midlands Cancer Intelligence Unit was over $40 \%$ in 1996. Many cases of lung cancer present in a terminal phase and, whilst it is recognised that some of these should perhaps have accessed the health care system earlier, a significant number of cases have truly malignant disease with very few symptoms right up until death.

This "denominator decrease" is also apparent in a frequently quoted paper from Belgium in which the study population was restricted to those who attended the hospital clinic. ${ }^{4}$ Examination of the paper quoted from the USA by Humphrey et ap shows that the denominator is reduced further as it excludes patients who had a histological diagnosis made at necropsy.

It is useful to refer back to a British paper published in the last decade based upon Cancer Registry data. Watkin $e t$ al ${ }^{6}$ quoted a $45 \%$ surgical intervention rate in patients with a histological diagnosis, considerably higher than elsewhere in the world. However, this represented a resection rate of $12 \%$ for all registered lung cancer patients. Data from the West Midlands Cancer Intelligence Unit show that the resection rate in 1996 was $20 \%$ for patients who had their lung cancer histologically confirmed before death yet $10.4 \%$ if all notifications were included in the denominator. Comparisons of process measures have their problems which are only made worse when the denominator is not comparable.

The results published by Laroche $e t$ al are interesting but longer term figures are needed to ensure that the described resection rates do not fall and, more importantly, that better patient outcomes are also observed, which are to be expected, if more patients are undergoing curative procedures. Whilst important points have been emphasised about access and information for the population, we must also strive towards comparing outcomes of care rather than just process detail. Furthermore, if process is to be compared, let us ensure that like is compared with like, an argument rightly used with respect to outcomes (case mix, stage etc).

Patients with lung cancer should have good quality care and good outcomes: this is rightly the message made by Laroche et al, not a dogma based upon spurious process comparisons.

ADRIAN PHILLIPS Wolverhampton Health Authority, Coniston House, Chapel Ash Wolverhampton WV3 OXE
GILL LAWRENCE West Midlands Cancer Intelligence Unit, Public Health Building, The University of Birmingham, Birmingham B15 2TT,

$U K$

1 Laroche C, Wells F, Coulden R, et al. Improving surgical resection rate in lung cancer. Thorax 1998;53:445-9.

2 Fountain SW. Surgery for lung cancer. Thorax 1998;53:441.

3 Danhuis RA, Schutte PR. Resection rates and postoperative mortality in 7899 patients with lung cancer. Eur Respir f 1996;9:7-10.

4 Deneffe G, Lacquet LM, Verbeken E, et al. Surgical treatment of bronchogenic carcinoma: a
retrospective study of 720 thoracotomies. Ann retrospective study of 720 thor
Thorac Surg 1998;45:380-3.

5 Humphrey EW, Smart CR, Winchester DP, et al. National survey of the pattern of care for carcinoma of the lung. 7 Thorac Cardiovasc Surg 1990;100:837-43.

6 Watkin SW, Hayhurst GK, Green JA. Time trends in the outcome of lung cancer management: a study of 9090 cases diagnosed in the Mersey Region, 1974-86. Br f Cancer 1990;61:590-6.

AUTHORS' REPLY We agree with the letter by Dr Phillips and Dr Lawrence concerning the difficulty of defining the denominator for an accurate surgical resection rate. In Papworth we do know that the two stop lung cancer service has led to more than a doubling of the total number of patients undergoing surgical resections at Papworth. There was no increase in the number of patients undergoing pneumonectomy compared with lobectomy, failed thoracotomies, or increase in stage of disease. This surgical resection rate has persisted since the start of the two stop service in 1995 and has continued to increase. Interestingly, regions serviced by the surgical unit at Pap worth that do not use the two stop service have also reported an increase in the number of patients being referred for surgery in the last year. However, this increase has been associated with an increase in the failed thoracotomy rate and also with an increase in the 
number of patients undergoing pneumonectomy compared with lobectomy. We conclude that before the two stop service was established there was a significant number of patients with operable disease who were not being identified, but that multidisciplinary review of potentially operable patients is necessary to prevent inappropriate referrals for surgery.

C M LAROCHE Papworth Hospital, Papworth Everard, Cambridge CB3 8RE $U K$

\section{Surgical resection rate in lung cancer}

We read with interest the study of Laroche et $a l .{ }^{1}$ Clearly the system they describe with a multidisciplinary clinic and specialist surgical input will enhance the investigative process and so probably improve the quality of the care of patients presenting to a respiratory service with possible lung cancer. We commend the authors on this.

We do, however, have serious questions as to whether the resection rate of $25 \%$ quoted is actually a true reflection on the resection rate for the whole population of patients with lung cancer within the area. In other words, it is essential to know what the absolute denominator was.

A review of registry data in the former Yorkshire region shows that only half the patients with lung cancer present in the "classical" way to a respiratory physician with a prior diagnosis of possible lung cancer. Virtually all patients who do prove operable are found in the half who present in the classical way. If experience is similar in East Anglia, then the denominator should be doubled.

In addition, we are concerned that some patients with advanced chronic obstructive disease or metastatic lung cancer would not have been referred to the clinic by the nine screening chest physicians. Moreover, the reason that small cell lung cancers were excluded from the denominator is unclear, and again will improve the apparent resection rate. We note that a number of patients were referred direct specifically for surgery from outwith the area, so increasing the numerator.

The authors describe an innovative process for the management of the patient with presumed lung cancer. However, it would be inappropriate to regard the $25 \%$ resection rate quoted as a benchmark and a possible audit standard for other lung cancer services, particularly where comorbidity is likely to be higher than in East Anglia.

C K CONNOLIY

Consultant Physician Darlington, UK

I JOHNSTON

Consultant Physician,

Nottingham, UK

R MILROY

Consultant Physician,

Glasgow, UK

R JONES

Consultant Oncologist

Glasgow, UK

1 Laroche C, Wells F, Coulden R, et al. Improving urgical resection rate in lung cancer. Thorax 1998;53:445-9.
AUTHORS' REPLY We agree with the above signatories that our surgical resection rate of $25 \%$ may not reflect the resection rate for the whole population of lung cancer patients within the area. What is certain is that our investigation process immediately led to a significant increase in the overall number of patients being referred for surgical resection from within the referral region, and that the number has continued to rise with the increased number of referrals into the system. We have found problems ourselves in attempting to obtain a true figure for overall resection rates.

Cancer registry data include patients who have not undergone histological confirmation and, as we have found from our service, many patients with presumed lung cancer have in reality alternative diagnoses. However, recognising that virtually all patients who do prove operable present in the classical way to chest physicians, it is important to note that, as mentioned in our paper, resection rates of patients with histologically confirmed lung cancer are still less than $10 \%$ in some units.

We would therefore propose that, while continually trying to increase the proportion of patients undergoing histological confirmation, the surgical resection rate of patients with confirmed non-small celllung cancer would be the most useful benchmark audit indicator for lung cancer services.

C M LAROCHE Papworth Hospital, Papworth Everard, Cambridge CB3 8RE,

\section{Repeatability of breathlessness measurements in cancer patients}

Visual analogue scales (VAS) and numerical rating scales are commonly used to assess breathlessness in patients with cancer. ${ }^{1-3}$ Their repeatability in this situation has not, however, been assessed in a way that allows calculation of the sample size required to design studies with sufficient power to detect a change in breathlessness. We asked 31 patients with breathlessness due to cancer to complete a $100 \mathrm{~mm}$ VAS and a numerical rating scale (from 0 to 10 ) on three occasions, twice on one day one hour apart and then again after a mean (range) of 2 (1-8) days. Patients were asked to rate their breathlessness "right now" and the worst and average severity of breathlessness and the degree of bother it had caused in the preceding 24 hours. Identical words were used to anchor the ends of both scales-for example, "not breathless at all" and "breathlessness as bad as you can imagine".

Sample sizes were calculated using the following equation ${ }^{4}$.

Table 1 Sample size required to detect a change in breathlessness of $25 \%$ for VAS and the numerical rating scale

\begin{tabular}{lll}
\hline & Visual analogue scale & Numerical rating scale \\
\hline Breathlessness 'right now' & $50(25 ; 13)$ & $31(3.0 ; 1.2)$ \\
Worst breathlessness over the past 24 hours & $36(51 ; 22)$ & $14(5.8 ; 1.4)$ \\
Average breathlessness over the past 24 hours & $30(33 ; 13)$ & $28(3.7 ; 1.4)$ \\
Bother over the past 24 hours & $67(36 ; 22)$ & $38(3.8 ; 1.7)$ \\
\hline
\end{tabular}

* The mean rating of breathlessness and the standard deviation of the difference between the two tests are given in parentheses. where $\sigma=$ the standard deviation of the difference between tests, $\delta=$ a specified reduction in the mean, $Z=$ the critical values from the Normal distribution to achieve the selected levels of significance and power, $\alpha=$ level of significance, and $\beta=$ the power of the test. Table 1 illustrates the sample sizes required to have a reasonable chance of detecting the effect of an intervention that reduced breathlessness scores over a few days in patients

$n=\left[\frac{\sigma}{\delta}\right]^{2}\left(\mathrm{Z}_{1-\alpha / 2}+\mathrm{Z}_{1-\beta}\right)^{2}+2 \mathrm{Z}_{1-\alpha / 2}$

with cancer by $25 \%(p=0.05$; power $=90 \%)$

The sample size required, reflecting the repeatability, varies with the particular aspect of breathlessness being measured. The numerical rating scale was a more repeatable measure than the VAS. We conclude that many studies that have examined the effect of an intervention on breathlessness in patients with cancer have not had sufficient power to detect a $25 \%$ change following the intervention.

$$
\begin{array}{r}
\text { A WILCOCK } \\
\text { V CROSBY } \\
\text { D CLARKE } \\
\text { A TATTERSFIELD } \\
\text { Nottingham City Hospital, } \\
\text { Nottingham } \\
\text { NG5 } 1 P B, U K
\end{array}
$$

1 Bruera E, Macmillan K, Pither J, et al. Effects of morphine on the dyspnea of terminal cancer patients. $f$ Pain Symptom Management 1990;5:341-4

2 Corner J, Plant H, A'Hern R, et al. Nonpharmacological intervention for breathlessness in lung cancer. Palliative Med 1996;10:299-305.

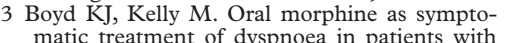
advanced cancer. Palliative Med 1997;11:27781.

4 Machin D, Campbell MJ. Statistical tables for the design of clinical trials. Oxford: Blackwell Scientific, 1987.

The BTS guidelines for the management of chronic obstructive pulmonary disease (COPD) state that use of ventilatory support or doxapram should be considered during acute exacerbations of respiratory failure in patients with arterial $\left[\mathrm{H}^{+}\right]>55 \mathrm{nmol} / \mathrm{l}(\mathrm{pH}$ <7.26), ${ }^{1}$ which implies that these measures should not be considered when $\left[\mathrm{H}^{+}\right]$is below this level. The paper cited to support this recommendation reported an uncontrolled prospective study of the application of guidelines including this criterion in COPD management, ${ }^{2}$ but the figure of $\left[\mathrm{H}^{+}\right]$ $>55 \mathrm{nmol} / \mathrm{l}$ originated from much earlier work observing that this degree of acidosis predicted increased mortality. ${ }^{3}$ The prospective study was not designed to test the hypothesis that only patients with $\left[\mathrm{H}^{+}\right]>55 \mathrm{nmol} / 1$ should receive respiratory support, and noted, firstly, that clinical judgement led to doxapram being given at lower levels of $\left[\mathrm{H}^{+}\right]$in 10 of 37

\section{COPD guidelines}


episodes in which it was used and secondly that, on retrospective analysis, $\left[\mathrm{H}^{+}\right]>53 \mathrm{nmol} /$ $(\mathrm{pH}<7.28)$ was a better predictor of mortality. ${ }^{2}$ The only placebo controlled trial of doxapram for respiratory failure in COPD demonstrated improvement in blood gas parameters in patients with a mean arterial $\left[\mathrm{H}^{+}\right]$of $46 \mathrm{nmol} / \mathrm{l}(\mathrm{pH} 7.34),{ }^{4}$ and recent controlled trials of non-invasive ventilation have also shown benefit in subject groups with a mean $\left[\mathrm{H}^{+}\right]$below $55 \mathrm{nmol} / 1 .{ }^{56}$ There is a risk that strict application of the BTS guidelines may result in treatment being delayed or withheld from patients with respiratory failure and worsening acidosis on controlled oxygen therapy whose $\left[\mathrm{H}^{+}\right]$has not risen to $55 \mathrm{nmol} / \mathrm{l}$, when there is no definitive evidence that such patients cannot benefit from doxapram or ventilatory support. Further trials are clearly needed to define more precisely which patients can benefit from these treatments, but meanwhile can I suggest that this recommendation be reconsidered?

ADAM WHITTLE

Chest Heart and Stroke Scotland Research Fellow, Respiratory Medicine Unit Western General Hospital, Edinburgh EH4 2XU, UK

1 British Thoracic Society. BTS guidelines for the management of chronic obstructive airways 1997:52(Suppl 5):S19.

2 Jeffrey AA, Warren PM, Flenley DC. Acute hypercapnic respiratory failure in patients with chronic obstructive lung disease: risk factors and use of guidelines for management. Thorax 1992;47:34-40.

3 Hutchison DCS, Flenley DC, Donald KW Controlled oxygen therapy in respiratory failure. BM7 1964;2:1159-66.

4 Moser KM, Luchsinger PC, Adamson JS, et al. Respiratory stimulation with intravenous doxapram in respiratory failure. $\mathrm{N} \mathrm{Engl} \mathrm{F} \mathrm{Med} \mathrm{1973;}$ 288:427-31.

5 Bott J, Carroll MP, Conway JH, et al. Randomised controlled trial of nasal ventilation in structive airways disease. Lancet 1993;341: 1555-7.

6 Brochard L, Mancebo J, Wysocki M, et al. Noninvasive ventilation for acute exacerbations of invasive ventilation for acute exacerbations of
chronic obstructive pulmonary disease. $N$ Engl chronic obstructive pulm

AUTHOR'S REPLY Dr Whittle's inference from the COPD guidelines was not one that we intended to imply. Lack of comment about the use of doxapram at $\mathrm{pH}$ levels greater than 7.26 reflects the paucity of data available and the lack of clinical agreement amongst those producing the guidelines. Usage varies substantially between hospitals and the relative position versus non-invasive ventilation is unclear.

There was agreement that respiratory failure should be actively managed according to the changing acid-base balance and that a $\mathrm{pH}$ of less than 7.26 should always be a cause for action. Lesser degrees of acid-base abnormality require clinical interpretation but would agree that patients with COPD and respiratory failure should not be denied active management.

M G PEARSON

Aintree Hospitals NHS Trust, University Hospital Aintree, Liverpool L9 $7 A L, U K$

\section{BOOK REVIEW}

Lecture Notes on Respiratory Medicine. 5th Edition. Bourke SJ. (Paperback, 205 pp. £14.95). UK: Blackwell Science, 1998. ISBN 0632049685.

In the preface to the fifth edition of this book, the author's stated aim is to provide a summary of current respiratory medicine for the medical student, junior doctors preparing for examinations, and general physicians undertaking continuing medical education.

The first chapter deals with the anatomy and physiology of the respiratory system and the second covers history taking and examination. The chapter on pulmonary function tests includes well annotated examples of spirometric tracings and flow-volume loops. The chapter on radiology includes clear diagrams and radiographs. There is a particularly helpful figure which explains the often confused anatomy of the mediastinum as seen on CT scanning.

The following chapters cover the full range of respiratory conditions. They are short but do not stint on detail. Topics covered include up to date opinion on the aetiology and pathology of asthma, advances in the understanding and treatment of cystic fibrosis, the current global epidemic of tuberculosis, current BTS guidelines on the management of asthma and COPD, and a lucid section on the respiratory manifestations of AIDS. Throughout, the text is supplemented by well laid out tables, graphs, and figures from important papers and generally well reproduced radiographs and CT scans. A feature particularly enjoyed were the numerous (and some humorous) line drawings by R A L Brewis himself, including the memorable "blue bloater and pink puffer" picture on page 117 .

In its aim to provide a text book for undergraduates, junior doctors, and general physicians this work succeeds admirably. As an aid to ward and clinic based learning it has the distinct advantage over its predecessor of fitting into the pocket of a white coat (just). Its attention to detail and clarity will make it a useful work for those undertaking postgraduate examinations and those generalists updating their knowledge of the subject.-AM

\section{NOTICES}

\section{0th British Association of Day Surgery}

The 10th annual scientific meeting and exhibition of the British Association of Day Surgery (BADS) will be held at Bournemouth International Centre, Bournemouth, UK on 3-5 June 1999. The deadline for abstracts is 31 March 1999. Enquiries regarding registration, abstracts and the exhibition should be addressed to: Kite Communications, The Silk Mill House, 196 Huddersfield Road, Meltham, West Yorkshire HD7 3AP. Tel: 01484 854575. Fax: 01484854576 e mail: info@kitecomms.co.uk. Enquiries regarding BADS membership should be addressed to: British Association of Day Surgery, 34-43 Lincoln's Inn Fields, London WC2A 3PA, UK. CME applied for.

\section{COPD: New Developments and Therapeutic Opportunities}

A course on "COPD: New Developments and Therapeutic Opportunities", suitable for physicians or scientists with an interest in the pharmacology and therapeutics of COPD, organised by Professor Peter Barnes will be held on 14-16 June 1999 at Imperial College School of Medicine at National Heart \& Lung Institute in collaboration with Royal Brompton Hospital, Dovehouse Street, London. For further information contact the Postgraduate Education Centre, National Heart \& Lung Institute, Dovehouse Street, London SW3 6LY, UK. Tel: 01713518172 . Fax: 0171376 3442 .

\section{CORRECTION}

\section{Respiratory symptoms and home environment in children}

In the paper entitled "Respiratory symptoms and home environment in children: a national survey" by M L Burr et al which appeared on pages $27-32$ of the January 1999 issue of Thorax, the authors regret that three lines were transposed in table 2 . The corrected section of this table relating to housing is shown below.

In addition, the address of Professor D P Strachan was omitted from the address panel on the first page of the paper. His address is: Department of Public Health Sciences, St George's Hospital Medical School, London SW17 0RE,

UK

Percentage prevalence of symptoms in children in each environmental group

\begin{tabular}{|c|c|c|c|c|c|c|c|c|c|c|c|}
\hline $\begin{array}{l}\text { Environmental } \\
\text { factor }\end{array}$ & Total no. & Wheeze & $\begin{array}{l}\text { Speech limiting } \\
\text { wheeze }\end{array}$ & $\begin{array}{l}\text { Wheeze } \\
\text { without colds }\end{array}$ & $\begin{array}{l}\text { Rhinitis, } \\
\text { itchy eyes }\end{array}$ & $\begin{array}{l}\text { Spring/ } \\
\text { summer rhinitis }\end{array}$ & $\begin{array}{l}\text { Cough with- } \\
\text { out colds }\end{array}$ & $\begin{array}{l}\text { Phlegm } \\
\text { with colds }\end{array}$ & $\begin{array}{l}\text { Phlegm } \\
\text { without colds }\end{array}$ & $\begin{array}{l}>3 \text { colds per } \\
\text { year }\end{array}$ & $\begin{array}{l}\text { Dry night cough } \\
\text { without colds }\end{array}$ \\
\hline \multicolumn{12}{|l|}{ Housing } \\
\hline Owned & 18338 & 33.5 & 8.3 & 21.2 & 17.9 & 6.7 & 27.2 & 62.0 & 19.7 & 26.3 & 43.7 \\
\hline Council & 5059 & 34.4 & 10.0 & 22.1 & 20.6 & 5.8 & 36.2 & 58.3 & 26.3 & 30.1 & 50.6 \\
\hline Other rented & 1013 & 34.9 & 9.7 & 21.5 & 21.4 & 7.4 & 32.7 & 63.2 & 23.2 & 27.9 & 47.0 \\
\hline Other & 983 & 36.5 & 11.0 & 22.5 & 20.3 & 5.9 & 32.8 & 58.9 & 22.2 & 30.5 & 48.8 \\
\hline
\end{tabular}

